\title{
Promoção por antiguidade na magistratura
}

Conselho Nacional de Justiça (CNJ)

Procedimento de Controle Administrativo 0000710-64.2011.2.00.0000

Requerente: Roberto da Fonseca Araújo

Requerido: Tribunal de Justiça do Estado do Espírito Santo

Advogado(s): ES012651 - Cristina Daher Ferreira (REQUERENTE)

PROMOÇÃO POR ANTIGUIDADE. REJEIÇÃO DO MAGISTRADO MAIS ANTIGO. APURAÇÃO DO QUORUM DE VOTAÇÃO. COMPOSIÇÃO INTEGRAL DO TRIBUNAL. NULIDADE DA DECISÃO DE RECUSA. PEDIDO DE CONTROLE PROCEDENTE. MODULAÇÃO DE EFEITOS.

1. Cômputo do quorum qualificado para recusa de promoção de magistrado que deve ser feito com base na composição integral do Tribunal.

2. Cômputo do quorum que, no caso, deve ser feito com base no número de cargos do Tribunal, ou seja, 26 (vinte e seis). Quórum de 2/3, necessário para se determinar a rejeição da promoção (art. 93, II, "d", da Constituição), que exige, portanto, a manifestação de 18 (dezoito) desembargadores. Precedentes.

3. Nulidade da decisão de recusa pela inobservância do quorum constitucional. Impossibilidade de se computar o voto de desembargador licenciado por motivo de saúde.

4. Modulação de efeitos. Viabilidade de solução do caso concreto sem ameaça à situação consolidada pela nomeação e posse do segundo magistrado mais antigo. Nulidade que se restringe à recusa. 
5. Pedido que se julga procedente para declarar a promoção do requerente pelo critério da antiguidade em vaga oferecida posteriormente.

\section{Relatório}

Trata-se de Procedimento de Controle Administrativo proposto pelo juiz de direito ROBERTO DA FONSECA ARAÚJO contra decisão plenária do Tribunal de Justiça do Estado do Espírito Santo (TJES) que recusou sua promoção à vaga de desembargador, à qual concorria pelo critério de antiguidade.

O requerente aduz, em síntese, que não foi observado o quorum mínimo fixado no art. 93, II, "d" da CF/1988 para a recusa da sua promoção; que houve voto de desembargador licenciado por motivo de saúde, o que macularia a eleição; e que a alteração do Regimento Interno do TJES, que não permitia o acesso ao Tribunal de juiz que respondesse a processo disciplinar, não poderia ser aplicada em seu caso porque o fato que deu ensejo ao procedimento disciplinar foi anterior à alteração. Sustenta, ainda, que a instauração do procedimento administrativo disciplinar foi lastreada em denúncia anônima e idealizada para impedir sua promoção.

Quanto ao primeiro fundamento, alega que o quorum mínimo de dois terços dos membros do respectivo tribunal recai sobre a totalidade de desembargadores. Sendo o Tribunal de Justiça do Espírito Santo composto por 26 desembargadores, não obstante estarem vagos três cargos, o quorum mínimo para rejeitar o juiz mais antigo seria de 18 votos. Ocorre que - e é aqui que se firma o segundo argumento - houve voto de desembargador que se encontrava licenciado para tratamento de saúde. Segundo afirma o requerente, ao votar, o referido desembargador teria violado o art. 16 do RITJ/ES que expressamente vedava a possibilidade de se colher o voto de integrante do Tribunal que estivesse em gozo de licença saúde. Assim, como seriam necessários 18 votos e houve vício no 17ํㅡ não teria sido atingido o quorum mínimo necessário para se determinar a recusa da promoção.

Sustenta, ainda, que a fundamentação para a recusa não foi razoável porquanto a existência de procedimento administrativo disciplinar contra si não poderia ser motivo suficiente para amparar a decisão de recusa.

Nesse particular, o requerente assevera que, a despeito do art. 90, parágrafo único, inc. III do RITJ/ES, dispor que a existência de procedimento administrativo disciplinar contra magistrado constitui hipótese de inabilitação do 
candidato à promoção, o Tribunal requerido fundamentou a recusa com base no referido dispositivo, o que teria prejudicado sua defesa.

Argumenta que, caso tivesse sido inabilitado nos termos do RITJ, teria a oportunidade de impugnar tal decisão antes da sessão de julgamento da promoção. Todavia, segundo o requerente, o Tribunal se utilizou de uma manobra para surpreendê-lo com a recusa de sua promoção.

Ainda buscando afastar a aplicação do art. 90 do RITJ ao caso, o magistrado sustenta que tal norma é posterior ao fato que deu azo ao referido procedimento administrativo disciplinar, de modo que, tendo em vista o princípio da irretroatividade da norma incriminadora maléfica, o dispositivo regimental não poderia ter sido aplicado na hipótese.

Alega, também, que, nos termos da Resolução n. 106 deste Conselho, a aplicação de pena disciplinar a magistrado, nos últimos 12 meses, constitui óbice apenas para as promoções pelo critério de merecimento.

E complementa, afirmando que, segundo o art. 15 da Resolução n. 30, no caso de aplicação das penas de censura e remoção compulsória apenas ficaria impedido de concorrer à promoção ou remoção o juiz não vitalício, situação na qual não se enquadra.

Daí por que o ato normativo expedido pelo TJ não poderia criar regramento novo restritivo de direito que não tenha previsão na Loman ou nas Resoluções deste Conselho.

Acrescenta que o precedente deste Conselho que lastreou a decisão atacada não deve ser aplicado à espécie porquanto restou superado pela edição da Resolução n. 106/2010.

Nada obstante entender que a instauração do procedimento administrativo disciplinar não configura motivo legal para a recusa de sua promoção, afirma que as notas taquigráficas da sessão e especialmente a manifestação do presidente do TJ evidenciam que o motivo determinante da recusa seria um suposto problema do requerente com alcoolismo. Em seu entender, porém, tal suposta enfermidade nunca foi objeto de regular apuração, não podendo, por isso, ter sido utilizada como fundamento para a recusa de sua promoção. Ademais, não havendo consonância entre os motivos reais e aqueles declinados na decisão atacada, teria havido violação da teoria dos motivos determinantes.

Por fim, requer, em sede de liminar, que o TJES se abstenha de promover concurso de promoção de magistrado até o julgamento final deste PCA e, no mérito, que este Conselho emposse o Requerente naquela segunda vaga disponibilizada para critério de antiguidade, mas não preenchida na sessão de julgamento do dia 06/12/2010. 
O relator que me antecedeu indeferiu a liminar por não vislumbrar perigo de dano, considerando que não havia notícia alguma de que o Tribunal requerido promoveria novo concurso de promoção ou outro ato capaz de causar prejuízo irreparável ao requerente (ACOR32).

Instado a se manifestar, o Tribunal rejeita a alegação de falta de quorum mínimo para a recusa da promoção, alegando que, nos termos do art. 11 da Lei Complementar Estadual n. 234/2002 (Código de Organização Judiciária), o TJES é composto por 26 desembargadores, de modo que, estando vagos três cargos, o quorum de 2/3 deve ser calculado sobre 23 membros efetivos, donde conclui que seriam necessários 15 votos e não 18, para a recusa da promoção.

Quanto ao voto do desembargador afastado por motivo de saúde, aduz que sua simples presença à sessão o habilitaria a votar.

Finalmente, quanto ao mérito da decisão impugnada, afirma que a rejeição do acesso do requerente ao TJES fundamentou-se em um conjunto de condutas incompatíveis com o exercício da magistratura constantes dos votos proferidos na sessão. Junta cópia de procedimentos instaurados em desfavor do requerente para apuração de condutas tidas como incompatíveis com a Loman e o Código de Ética da Magistratura.

Em requerimento para a juntada de novos documentos (PET138), afirma o requerente que na instrução do procedimento administrativo disciplinar que serviu de fundamento para a recusa, houve indução de testemunha de forma a macular a sua imagem; que há possível suspeição do desembargador corregedor na condução do procedimento investigatório anterior ao procedimento disciplinar, arguida formalmente; que a instauração do procedimento administrativo disciplinar ocorreu em função de uma carta apócrifa cujo incidente de falsidade está sendo arguido.

No evento n. 24, mais uma vez o requerente vem aos autos (PET148) para afirmar que os procedimentos investigatórios contra si instaurados objetivam claramente impedir o seu acesso ao Tribunal. Nesse contexto, quanto à sindicância n. 1015815, colacionada pelo requerido, o autor afirma que ela seria decorrência de uma retaliação do desembargador ouvidor, que teria se sentido ofendido pelo fato de ter sido questionado sobre a existência da noticiada carta apócrifa que supostamente teria recebido e que deu origem ao já mencionado procedimento administrativo disciplinar instaurado em seu desfavor.

Reiterou, ainda, os argumentos anteriormente desenvolvidos, em especial quanto à nulidade do procedimento administrativo disciplinar que teria ensejado a recusa da sua promoção. Requereu, novamente, o provimento cautelar a fim de que se suspendesse o edital n. 066/2011 no qual, segundo alega, o 
Tribunal requerido franqueara nova vaga de acesso ao $2^{\varrho}$ grau pelo critério da antiguidade. Ratificou, no mérito, o pedido exordial.

Uma vez mais, o relator que me antecedeu indeferiu o pleito cautelar, desta vez sob o fundamento de ausência do perigo na demora, porquanto o processo se encontrava na iminência de ser julgado (DEC151).

O Conselheiro PAULO TAMBURINI submeteu o feito a julgamento na 128 Sessão Ordinária, realizada em 7/6/2011, oportunidade na qual o Plenário deste Conselho decidiu converter o procedimento em diligência, para intimar o Tribunal requerido a apresentar cópia do procedimento de suspensão da licença saúde do desembargador William Couto.

Em 17/6/2011, o Tribunal informa que não houve suspensão formal da licença para tratamento de saúde do citado desembargador, no período de 29/11/2010 a 11/12/2010.

O requerente, por meio da PET158, manifesta-se sobre a informação do TJES, aduzindo que o comparecimento do des. William Couto se deu justamente para composição do quorum necessário para o julgamento das promoções, todavia, não tendo havido a suspensão formal de sua licença para tratamento de saúde, o seu voto estaria eivado de nulidade, nos termos do disposto no art. 16 do RITJ/ES. Daí, reitera a alegação de falta de quorum para a decisão de recusa de sua promoção por antiguidade.

No último dia 22, o requerente solicitou cópia do áudio da 128a Sessão, na qual o julgamento do presente feito foi convertido em diligência. Pedido deferido na mesma data.

É o breve relatório.

\section{Voto}

O requerente insurge-se contra a decisão do Tribunal de Justiça do Estado do Espírito Santo que recusou sua promoção (acesso ao $2^{\circ}$ grau) por antiguidade pelas seguintes razões:

1) não teria sido alcançada a maioria qualificada de $2 / 3$ de que trata o art. 93, II, "d" da Constituição, pois:

(i) eram necessários 18 votos, vez que o cômputo da maioria qualificada deve ser feito com base na totalidade de cargos do tribunal $(26 \times 2 / 3=$ $17,33 \leftrightarrow 18)$; e

(ii) dentre eles foi computado o voto do desembargador William Couto, que participou da sessão quando estava em gozo de licença para tratamento de saúde; e 
2) a recusa estaria amparada na existência de processo disciplinar instaurado contra o requerente:

(i) quando na realidade os votos se basearam em matéria de fato não submetida ao contraditório e à defesa do requerente, qual seja, um suposto problema de saúde do requerente, violando o princípio da motivação;

(ii) contra o disposto no art. 90, parágrafo único, inc. III do Regimento Interno do TJES, segundo o qual a existência de procedimento disciplinar é motivo de inabilitação e não de recusa, o que impediu o exercício da ampla defesa e o contraditório antes da deliberação sobre a promoção, violando a norma do art. 5ํ, LV da Constituição Federal;

(iii) contra o disposto na Resolução n⿳o 106 deste Conselho, que somente prevê a recusa quando o magistrado tiver sofrido sanção igual ou superior à de censura nos últimos 12 meses;

(iv) com o único propósito de impedir sua futura promoção e por meio de documento cuja falsidade já foi arguida;

(v) com base em denúncia anônima, o que seria vedado pelo art. 5o, IV da Constituição; e

(vi) com base em fato ocorrido antes da inclusão no regimento interno do tribunal da restrição referente à existência de processo disciplinar, violando a aplicação analógica do princípio da não retroatividade da lei penal;

Por sua vez, o Tribunal de Justiça do Espírito Santo sustentou que (INF35):

1) a maioria absoluta seria alcançada com o voto de 15 (quinze) desembargadores, visto que 3 (três) dos 26 (vinte e seis) cargos de desembargador estariam vagos $(23 \times 2 / 3=15,33$ ๑ 15$)$, o que já autorizaria a recusa mesmo a não se considerar o voto do des. William Couto que, de todo modo, estaria habilitado a votar pelo simples comparecimento; e

2) "não obstante o entendimento já esposado pelo CNJ no sentido da legalidade do condicionamento de participação de magistrado em procedimento de promoção à ausência de existência de PROCEDIMENTO ADMINISTRATIVO DISCIPLINAR contra si instaurado", a votação foi devidamente fundamentada "em um conjunto de condutas incompatíveis com o exercício da magistratura", sendo o requerente "rejeitado por sua conduta incompatível com os preceitos do Código de Ética da Magistratura Nacional e da Lei Orgânica da Magistratura e não inabilitado de forma apriorística pelo simples fato de estar respondendo a um procedimento administrativo disciplinar". 
Penso ser questão preliminar a este julgamento a definição da quantidade mínima de votos exigida para a recusa na ocasião em que foi votada a promoção por antiguidade do requerente (6.12.2010).

O Tribunal de Justiça do Estado do Espírito Santo é composto de 26 desembargadores, nos termos do que dispõe o art. 11 da Lei Complementar Estadual n. 234/2002 (Código de Organização Judiciária) e assim o era na data da sessão em que se deliberou a recusa da promoção por antiguidade do requerente (DOC23 a 27).

Naquela ocasião, 3 (três) cargos encontravam-se vagos, de modo que, no máximo, apenas 23 (vinte e três) desembargadores poderiam deliberar e votar.

Dispõe o art. 93, II, "d", da Constituição:

Art. 93. (...):

(...)

II. (...)

(...)

d) na apuração de antiguidade, o tribunal somente poderá recusar o juiz mais antigo pelo voto fundamentado de dois terços de seus membros, conforme procedimento próprio, e assegurada ampla defesa, repetindo-se a votação até fixar-se a indicação (grifei).

Por conta dessa redação, instaurou-se controvérsia quanto ao número que deveria ser tomado como o número de membros do tribunal.

O requerente defende que deveriam ser 18, vez que a maioria qualificada deveria ser calculada com base no número de cargos do tribunal. O requerido, por sua vez, sustenta que deveriam ser apenas 15 , calculada a maioria qualificada com base apenas nos cargos efetivos.

No julgamento da Revisão Disciplinar no 0002882-81.2008.2.00.0000, de relatoria do eminente conselheiro MILTON NOBRE, este Conselho entendeu que a maioria qualificada, pelo menos em casos disciplinares, deveria ser calculada com base na composição integral do tribunal:

Revisão Disciplinar. Alegação de nulidade no julgamento de procedimento administrativo disciplinar. Convocação de juízes de $1^{a}$ instância. Violação do quorum constitucional. Art. 93, incisos VIII e X.

Não se admite a convocação de juízes de 1in instância para composição de quorum em julgamentos de natureza administrativa e, especialmente, disciplinar, ante a redação dada ao art. 93, inciso $X$, da Constituição da República. 
O cálculo da maioria absoluta, apurado a partir do número de membros votantes, sem se considerar a composição integral do Tribunal, constitui regra de exceção criada para norma constitucional, cuja interpretação há de ser restritiva, uma vez que a exigência de quorum qualificado, na espécie, significa reserva para blindagem das garantias da magistratura previstas no art. 95 da Constituição Federal.

Revisão disciplinar julgada parcialmente procedente.

Assim o fez com fulcro em interpretação extraída do brilhante voto do ministro SYDNEY SANCHES no julgamento do RE 103.700/MG, ocasião em que a Suprema Corte, julgando situação que envolvia remoção compulsória e disponibilidade de magistrado, declarou incidentalmente a inconstitucionalidade do parágrafo único do art. 24 da Loman. Este determinava que o "quorum de dois terços de membros efetivos do tribunal, ou de seu órgão especial, será apurado em relação ao número de desembargadores em condições legais de votar, como tal se considerando os não atingidos por impedimento ou suspeição e os não licenciados por motivo de saúde".

Segundo o voto do conselheiro MILTON NOBRE, a argumentação do ministro SYDNEY SANCHES leva à conclusão de que "não procede qualquer tentativa de se relativizar o quorum constitucionalmente qualificado para aplicação de penalidades como a de que trata o caso em exame, por via de interpretação diversa, vale dizer, que não seja a de se considerar, no cômputo do quorum exigido a integralidade dos membros do tribunal" (REVDIS n. 0002882-81.2008.2.00.0000, fl. 09).

Penso que, a despeito dos precedentes citados cuidarem da fixação de quorum de votação para aplicação de pena disciplinar e não terem enfrentado especificamente a questão relativa ao cômputo ou não como "membro" do Tribunal, dos cargos vagos, o mesmo raciocínio aplicado naquelas hipóteses deve ser reproduzido no caso.

É que, assim como naqueles julgados, a maioria qualificada foi constitucionalmente estabelecida com o fim de preservar as garantias e os princípios que regem a magistratura, arrolados por todo o art. 93 da CF/1988. Ademais, considerando a previsão de um quorum equivalente à maioria absoluta dos membros do tribunal (art. 98, VIII, da Constituição) e outro equivalente a 2/3 desses membros (art. 98, II, “d"), é possível inferir que nesta última hipótese - que é precisamente o caso dos autos - o cuidado dispensado à garantia protegida é ainda mais intenso e rigoroso.

Daí por que, na expressão consignada pelo eminente conselheiro MILTON NOBRE no voto que proferiu na citada revisão disciplinar, da sólida 
sustentação contida no voto do saudoso ministro [SYDNEY SANCHES], temse como certo que não procede qualquer tentativa de se relativizar o quorum constitucionalmente qualificado para aplicação de penalidades como a de que trata o caso em exame, por via de interpretação diversa, vale dizer, que não seja a de se considerar, no cômputo do quórum, exigida a integralidade dos membros do Tribunal.

Ressalte-se que toda a argumentação do voto condutor do julgamento no Supremo Tribunal Federal gira em torno da garantia da inamovibilidade, que não se compatibilizaria com o enfraquecimento da barreira procedimental erigida contra a remoção compulsória e a disponibilidade de juízes, que era exatamente o caso daquele julgamento:

As considerações feitas até aqui, de ordem histórico-legislativa, doutrinária e jurisprudencial e a leitura do inciso II e seu § 3o do art. 113 da Constituição Federal em vigor, em conjugação com o parágrafo único do art. 112, permitem a conclusão de que, ao tratar da disciplina da magistratura, a Lei Orgânica Nacional não podia dispensar a exigência de 2/3 de votos dos juízes efetivos do Tribunal pela aplicação da medida.

Votos concordes pela aplicação.

"Quorum" inferior estaria afrontando a norma constitucional e a garantia, que ela representa" (grifei).

Ainda que o caso em tela não envolva o afastamento compulsório de magistrado de sua titularidade, nem a aplicação de penalidades ou sanções disciplinares, a premissa fixada na referida decisão da suprema corte há de ser aplicada à espécie, que também cuida dos princípios previstos no art. 93 da CF/1988.

É por essa razão que se pode extrair da referida decisão do Supremo Tribunal Federal a premissa de que o quorum qualificado exigido pela Constituição não pode ser relativizado , tanto nos casos de sanções disciplinares quanto nos casos de recusa da promoção por antiguidade, sob pena de se colocar em risco princípios e garantias que a própria Carta Magna colocou sob sua proteção. A relevância dessa proteção supera até mesmo o fato de que, quando se trata de acesso ao $2^{\circ}$ grau pelo critério de antiguidade, haverá, sempre e sempre, pelo menos um cargo não preenchido no tribunal.

Desse modo, considero, para fins do cômputo da maioria qualificada de 2/3 a que se refere o art. 93, II, "d", da Constituição, o número equivalente 
à integralidade de cargos do Tribunal, pelo que concluo que a recusa não poderia ser determinada sem o voto de 18 desembargadores $(26 \times 2 / 3=17,33$ $\leftrightarrow 18)$.

Ocorre que dentre os 18 votos que foram proclamados pelo excelentíssimo desembargador presidente do Tribunal de Justiça do Espírito Santo, um deles foi proferido pelo desembargador William Couto que, segundo confirmação do tribunal requerido, estava, naquela ocasião, em gozo de licença por motivo de saúde.

Ora, tal condição, pelo menos em minha concepção, impedia a participação do referido desembargador nas deliberações e, consequentemente, o cômputo de seu voto. Trata-se de caso de nulidade, visto não haver qualquer previsão do regimento interno do Tribunal que autorizasse a suspensão automática da licença.

Há, em verdade, dispositivo que impede a participação dos desembargadores em gozo de licença para tratamento de saúde na organização das listas referidas no Capítulo III do RITJ/ES, o que pode indicar o entendimento do próprio tribunal quanto à inviabilidade da participação de licenciados em decisões de cunho administrativo:

Art. 16 - Não poderão votar na organização das listas os Desembargadores, parentes consanguíneos ou afins, até o terceiro grau, dos candidatos, ou que estiverem em licença para tratamento de saúde.

De todo modo, não parece razoável que a mesma razão que justifica o cômputo do quorum qualificado de $2 / 3$ para recusa da promoção por antiguidade - a proteção de garantias da magistratura - assinta que, para a formação desse mesmo quorum, não sejam observadas formalidades mínimas como a suspensão ou cessação expressas da licença de desembargador que pretenda participar da respectiva deliberação.

Assim, nulo é o voto do referido desembargador.

Tal nulidade reduz a maioria de votos pela recusa a apenas 17 votos, quantidade que não atende ao quorum mínimo de $2 / 3$, equivalente a 18 votos.

Por todas essas razões, convenço-me da violação, no caso, do disposto no item " $\mathrm{d}$ ", do inciso II do art. 93 da Constituição, o que impede o reconhecimento da legalidade da decisão que recusou a promoção por antiguidade do requerente.

Logo, a própria proclamação do resultado impugnado ficou viciada, pois não sendo o caso de recusa o único resultado possível seria a promoção do 
requerente para o cargo de desembargador pelo critério de antiguidade. Outra solução não haveria. Insisto: não sendo alcançado o quorum constitucional, a única solução admitida seria a da promoção do requerente, o que põe em xeque a validade de todos os atos posteriores.

Entretanto, vejo que é possível chegar a uma solução que prestigie a economicidade dos atos administrativos e, ao mesmo tempo, não ameace eventuais situações já constituídas, como aquela da nomeação e posse do juiz Dair José Bregunce de Oliveira no cargo então oferecido à promoção por antiguidade.

Segundo consta dos autos, por ocasião da sessão do dia 6.12.2010, estavam em aberto três vagas para o acesso ao $2^{\circ}$ grau: uma por antiguidade (vaga disputada pelo requerente); uma por merecimento; e outra por antiguidade, sendo que esta última vaga não foi até o presente momento preenchida, embora tenha sido oferecida no mesmo edital que as demais (Edital no 66/2010).

Tal circunstância é que permite que se considere a possibilidade de sanear a irregularidade ora reconhecida, de forma a se evitar a declaração de nulidade de todos os atos posteriores à decisão atacada.

O próprio requerente parece conformar-se com uma tal solução ao, na formulação de sua pretensão, pleitear que:

este Órgão de Controle determine que o Egrégio Tribunal de Justiça do Estado do Espírito Santo emposse o Requerente naquela segunda vaga disponibilizada para critério de antiguidade, mas não preenchida na sessão de julgamento do dia 6/12/2010 (terceira vaga ofertada pelo edital que segue anexo para a qual também concorre este magistrado), harmonizando o interesse público envolvido com os interesses do magistrado em epígrafe.

Com efeito, vejo que a solução apontada é, de fato, a mais adequada às circunstâncias, pois faz justiça à pretensão do requerente e, ao mesmo tempo, mantém a situação já consolidada pela nomeação e posse do magistrado Dair José Bregunce de Oliveira.

Por tudo, entendo que, não obstante a invalidade da decisão que proclamou a recusa da promoção do requerente, a existência de vaga em aberto destinada à promoção pelo critério da antiguidade permite o reconhecimento do direito do requerente por meio da modulação dos efeitos da nulidade ora declarada, com a preservação dos atos relativos à promoção, nomeação e posse do magistrado acima indicado. 
Pelo exposto, julgo procedente o pedido para:

(i) declarar a nulidade da decisão proclamada na sessão do dia 6.12.2010 do TJES, que recusou a promoção por antiguidade do requerente, modulando seus efeitos para assegurar a validade dos atos de promoção, nomeação e posse do magistrado Dair José Bregunce de Oliveira;

(ii) declarar a promoção e nomeação do requerente para o cargo de desembargador do TJES, pelo critério da antiguidade; e

(iii) determinar ao TJES que, independentemente da publicação do acórdão da presente decisão, providencie e efetive a posse imediata do requerente no cargo de desembargador referente à segunda vaga por antiguidade oferecida no Edital n. 66/2010.

É como voto.

Esse documento foi assinado eletronicamente por JOSÉ GUILHERME VASI WERNER em 30 de agosto de 2011 às 09:20:01. 